\title{
Computer Vision Syndrome and Its Predictors Among Secretary Employees Working in Jimma University, Southwest Ethiopia
}

\author{
Mekonnin Tesfa ${ }^{1, *}$, Mohammed Ibrahim ${ }^{2}$, Yohannes Markos ${ }^{2}$, Ashete Adere ${ }^{1}$, Leyla Temam ${ }^{3}$ \\ ${ }^{1}$ Department of Biomedical Sciences, College of Health Sciences, Woldia University, Woldia, Ethiopia \\ ${ }^{2}$ Department of Biomedical Sciences, Institute of Health, Jimma University, Jimma, Ethiopia \\ ${ }^{3}$ Department of Biomedical Sciences, College of Medicine and Health Sciences, Wochamo University, Hossana, Ethiopia
}

Email address:

mtesfa165@gmail.com(M. Tesfa),mekonnin.tesfa@wldu.edu.et(M. Tesfa)

${ }^{*}$ Corresponding author

\section{To cite this article:}

Mekonnin Tesfa, Mohammed Ibrahim, Yohannes Markos, Ashete Adere, Leyla Temam. Computer Vision Syndrome and Its Predictors Among Secretary Employees Working in Jimma University, Southwest Ethiopia. International Journal of Sensors and Sensor Networks. Vol. 9, No. 1, 2021, pp. 11-18. doi: 10.11648/j.ijssn.20210901.12

Received: December 18, 2020; Accepted: December 29, 2020; Published: January 22, 2021

\begin{abstract}
Background: Computer users are at high risk to experience eye discomfort and vision problems when viewing digital screens for extended periods. These problems are collectively termed Computer Vision Syndrome (CVS). Nearly more than 60 million people suffer from CVS globally with a million new cases occurring each year. The magnitude of CVS and its determinants are not well known in Ethiopia. Thus, the aim of the study was to determine the prevalence of CVS and its predictors among secretary employees working in Jimma University, Ethiopia. Methods: An institution-based cross-sectional study was conducted on 217 secretary employees working at Jimma University. An interviewer-administered structured questionnaire was used to collect data. Data was collected through face to face interview. The collected data first entered Epidata version 3.1 and then transformed into SPSS version 20.0 for data analysis. Binary logistic regressions were carried out to determine variables associated with CVS. Results: The prevalence of CVS among study participants was $75.6 \%(95 \% \mathrm{CI}=70.0$, 81.1). Blurred vision 88 (40.6\%), extra-ocular symptoms $75(34.6 \%)$, eyestrain $66(30.4 \%)$, and headache $63(29.0 \%)$ were the most commonly reported symptoms of CVS. Duration of occupation $\geq 10$ years (Adjusted odds ratio (AOR) $=3.165$; $95 \% \mathrm{CI}=1.16$,) working on the computer on average for $\geq 6$ hours per day ( $\mathrm{AOR}=3.163 ; 95 \% \mathrm{CI}=1.52,6.59)$, not adjusting computer screen brightness $(\mathrm{AOR}=2.81 ; 95 \% \mathrm{CI}=1.22,6.47)$ and lack of awareness about $\mathrm{CVS}$ and its prevention measures $(\mathrm{AOR}=5.385 ; 95 \% \mathrm{CI}=2.55,11.35)$ were factors at higher risk of developing CVS. Conclusion: CVS is highly prevalent among secretary employees working at Jimma University. Arranging training program/health education to increase awareness on CVS and its prevention measures might minimize the risk of suffering CVS.
\end{abstract}

Keywords: Computer Vision Syndrome, Predictors, Work Place, Jimma University

\section{Introduction}

Our world has moved from a manufacturing society to an information society. In this $21^{\text {st }}$ century, where we are living in a highly sophisticated environment, a computer is one of the most dispensable electronic devices which is used presently almost by all age groups [1]. Globally, computers are one of the commonest office tools in various institutions such as government offices and academic institutions and its usage had become this century necessity [2].
The discovery of the computer has to a greater extent revolutionized most professions and their work performance. For instance, secretaries, accountants, bankers, academicians, journalists, engineers, flight controllers, and graphic artists are professionals who cannot work without the help of computers [3]. These days, it is not uncommon to see secretary employees spending a significant part of their day glued to computer screens because of their occupation. However, working on it is not free from health hazards, especially, close and prolonged use of computers is known to 
cause medical problems termed "Computer Vision Syndrome" $[4,5]$.

American Optometry Association (AOA) defined Computer Vision Syndrome (CVS) as a complex of eye and vision problems related to the activities which stress the near vision and which are experienced about or during the use of computers [6]. CVS is becoming the number one occupational epidemic of the $21^{\text {st }}$ century [7-9]. Globally, it is estimated that nearly 60 million people suffer from CVS with a million new cases occurring each year [10]. Several studies estimated that the worldwide prevalence of CVS ranges from $25 \%$ to $93 \%$ among computer users [11].

Studies have reported that the prevalence of CVS was $54.6 \%, 67.4 \%$, and $69.3 \%$ among operators of a call center in Brazil [12], office workers in Sri Lanka [10], information technology professionals in Chennai [13] respectively. Bali et al. reported that the most common CVS symptoms among study participants were eyestrain $(97.8 \%)$, headache $(82.1 \%)$, burning sensation $(79.1 \%)$, watering $(66.4 \%)$, and red eyes (61.2\%) among Indian Ophthalmologists [14].

A study conducted in Chennai among university students has shown that the prevalence of CVS was $78.6 \%$ among medical students whereas $81.9 \%$ among engineering students [2]. A study conducted among computer engineering students of university situated in Lahore, India reported the prevalence of CVS as $72.4 \%$ [15].

A study conducted in Gondar found the prevalence of CVS to be $73 \%$ among bankers [16]. Blurred vision (42.4\%), headache $(23.0 \%)$, red eyes $(23.0 \%)$ were the most experienced symptoms among bankers. It is not debatable that the use of computers is generally encouraged to keep up with the fast-moving world of technology, research, and science. The discomfort associated with prolonged and improper computer usage can significantly impair workplace productivity, increases error rate, reduces job satisfaction, and the quality of life by placing unusual strain on the human physical well-being [7].

The economic impact of the visual and musculoskeletal problems associated with improper and increased computer use is becoming high. Minimizing symptoms that reduce occupational efficiency will result in a substantial financial benefit [17]. For instance, the cost of diagnosis and treatment of CVS in the USA alone exceeds 2 billion annually which indicates a reflection of importance to think about this new emerging medical and visual problem [18]. CVS remains an underestimated and poorly understood condition at the workplace [19].

Several factors are associated with computer vision syndrome. Studies have shown that being female, longer duration of occupation, prolonged daily computer usage, improper sitting position, and not adjusting computer brightness all was associated significantly with the presence of computer vision syndrome [12, 20]. For instance, the Osaka study identified age above 30 years as a risk factor for computer use related dry eyes [4].

In today's world, millions of employees conduct their work activities sitting behind a computer for hours on end
[6]. Among these, secretaries are one of the workers that are occupationally obliged to carry out their daily activities facing a computer screen for a prolonged time. Working on computers for a prolonged time is believed to cause eye problems. Therefore, it very important to assess how much the burden is in this population group. It is a welldocumented fact that CVS is a worldwide problem and this is true especially in developed countries, but in our country Ethiopia, there is scarcity of data to show the magnitude of CVS and its determinants. Thus, this study aimed to determine the prevalence and predictors of computer vision syndrome among secretary employees working at Jimma University.

\section{Methods and Materials}

\subsection{Study Design, Area, and Period}

Institution based cross-sectional study was conducted in Jimma University from April to May, 2018. Jimma University is found in Jimma town, which is located in the Southwest part of Ethiopia in Oromia Regional State at a distance of $357 \mathrm{~km}$ from the capital city of Ethiopia, Addis Ababa. The establishment of Jimma University dates back to 1952 when Jimma College of Agriculture was founded. Currently, the University has four campuses (Main campus, Business, and Economics campus, College of Agriculture and Veterinary Medicine campus and Jimma Institute of Technology campus). According to the data obtained from human resource office, the University had a total of about 224 secretary workers including those working in Jimma University Medical Center at the time of data collection.

\subsection{Study Population and Eligibility Criteria}

The study population were all secretary employees working in the Jimma University. The inclusion criteria for this study were the duration of occupation greater than or equal to one year. Secretaries who were not available during data collection time due to illness or maternal leave, with eye disease and refractive errors, history of medical illness such as hypertension and diabetes mellitus were excluded from the study.

\subsection{Sample Size Determination}

Based on $73 \%$ prevalence of CVS from a previous study conducted among bank workers in Gondar town [16], applying single population proportion formula and correction formula the calculated sample size was 131. However, because of manageability of sample size all available secretaries were considered to be included in the study.

\subsection{Operational Definition}

Presence of CVS: Experiencing at least one of the following symptoms either intermittently or continuously for at least one week during the last twelve months with computer use was considered as 'presence of CVS'. The symptoms are blurred vision, double vision, eye strain, eye 
burning sensation, itching eye, red eyes, watery eyes, dryness of eyes, pain in and around the eyes, increased sensitivity to light, changes in color perception, and extraocular symptoms [10]. Extraocular symptoms: Symptoms including neck, back, and shoulder pain. Viewing distance: The distance from the eye to the computer screen in centimeter. Appropriate sitting position: The face of the worker just in level to the computer screen. Mild symptom: a symptom that persists for a few minutes to hours during computer use. Moderate symptom: a symptom that persists during computer use and subsides after rest. Severe symptom: a symptom that needs medical consultation [2].

\subsection{Data Collection Procedures and Quality Control}

An interviewer-administered questionnaire designed and validated by Seguí et al. [28] was used to collect information from participants. The questionnaire was initially developed in English and translated into working language (Amharic) and translated back into English language for keeping its consistency during data entry. Before the actual data collection, the questionnaire was pre-tested on 11 secretaries ( $5 \%$ of study population) working in Jimma town government officials to estimate the time needed to collect data and check the understandability of the words or sentences in the questionnaire. The training was given for data collectors before data collection regarding the purpose of the study, interview, and ethical issues during data collection. Data collectors were informed on how to fill the questionnaire. Three ophthalmic nurses were involved in data collection and overseen by the supervisor. The ophthalmic examinations were done to assess participant's visual acuity, eye/ocular diseases and refractive errors. The examination was done at study participants' actual work site. Data was collected using medical equipment's like ophthalmoscope, Pinhole occlude and Snellen E-chart (for visual acuity test). Meter tape was used to measure viewing distance. Data collectors have measured the viewing distance to the nearest 0.1 centimeter. The data were checked for completeness and consistency throughout the data collection period.

\subsection{Data Analysis Procedures}

Data were checked for completeness, coded, and entered into EPI-data version 3.1 and then transferred to SPSS version 25.0 for analysis. Frequencies, median, and percentage were used to give a clear picture of sociodemographic variables. Bivariate analysis was performed to select candidate variables at a $p$-value $\leq 0.25$. The variables that have statistically significant associations with the outcome variable in the bivariate analysis were further considered as a candidate for a multivariable logistic regression model to control the effect of confounding variables. Multivariable regression analysis was carried out to declare variables that are independently associated with CVS and AOR were used to indicate the strength of association between dependent and independent variables. The final model was assessed for goodness-of-fit using the
Hosmer-Lemeshow test. No evidence indicating a lack of fit was found $(p$-value $=0.221$ ). The model was tested for the presence of multicollinearity (Variance inflation factor (VIF) of 1.012-1.607) and no multicollinearity was found. Finally, those variables with $p$-value $<0.05$ in the final model were considered as statistically significant.

\subsection{Ethical Consideration}

Ethical clearance was obtained from the Institutional Review Board of Jimma University with ethical approval reference number IHRPGD/268/2018. Before data collection, a letter of permission to conduct the study was obtained from Jimma university human resource directorate. All study participants were given information on the study and written informed consent was obtained. Participant's confidentiality was maintained, and anonymity was ensured by using codes instead of names and any personal identifier of the participants.

\section{Results}

\subsection{Socio-demographic Characteristics}

Table 1. Socio-demographic characteristics of secretary employees in Jimma University, Ethiopia, 2018, $(n=217)$.

\begin{tabular}{llll}
\hline Characteristics & & Frequency & Percent (\%) \\
\hline \multirow{4}{*}{ Age } & $<=25$ years & 21 & 9.7 \\
& 26-35 years & 135 & 62.2 \\
& $>=36$ years & 61 & 28.1 \\
Religion & Orthodox & 111 & 51.2 \\
& Muslim & 40 & 18.4 \\
& Protestant & 39 & 18.0 \\
& Others* & 27 & 12.4 \\
Ethnicity & Oromo & 149 & 68.7 \\
& Amhara & 27 & 12.4 \\
Marital status & Others & 41 & 18.9 \\
& Married & 136 & 62.7 \\
& Single & 61 & 28.1 \\
Educational level & Others & 20 & 9.2 \\
& Certificate & 4 & 1.8 \\
Duration of occupation & Diploma & 116 & 53.5 \\
as a secretary & Degree & 97 & 44.7 \\
Average working hours & 1-<5 years & 57 & 26.3 \\
on the computer per day & 5-9 years & 89 & 41.0 \\
\hline
\end{tabular}

*Catholic \& Jehovah witness *divorced, separated and widowed ${ }^{\dagger}$ Tigre, Gurage, Kambata, Hadiya

A total of 224 study subjects were initially determined to be included in this study. However, a total of 217 study subjects were the actual study participants from which data were collected and analyzed, making a response rate of $96.8 \%$. All $217(100 \%)$ of the study participants were females. The age of study participants ranges from 21 to 48 years with the median (IQR) age of 31 (27 to 36 ) years. Of these, a majority of $135(62.2 \%)$ of the study participants belonged to the age category 26-35 years. Regarding the religion, $111(51.2 \%)$ study participants were Orthodox Christians followed by Muslim 40 (18.4\%), Protestant 39 
(18.0\%), and others $27(12.4 \%) .149(68.7 \%)$ of More than half study participants $116(53.5 \%)$ were diploma holders. Most $89(41.0 \%)$ of the study population had worked for about 5 to 9 years (Table 1 ).

\subsection{Prevalence of Computer Vision Syndrome}

The overall prevalence of CVS among the study population was $75.6 \%(95 \% \mathrm{CI}=70.0,81.1)$. In the present study, the most common reported symptom among study participants was blurred vision $88(40.6 \%)$, followed by extra-ocular symptoms $75(34.6 \%)$, eyestrain $66(30.4 \%)$ and headache $63(29.0 \%)$ whereas sensitivity to light $22(10.1 \%)$ and changes in color perception $21(9.7 \%)$ was the least complaint. The prevalence of each symptom of CVS is presented in Figure 1.

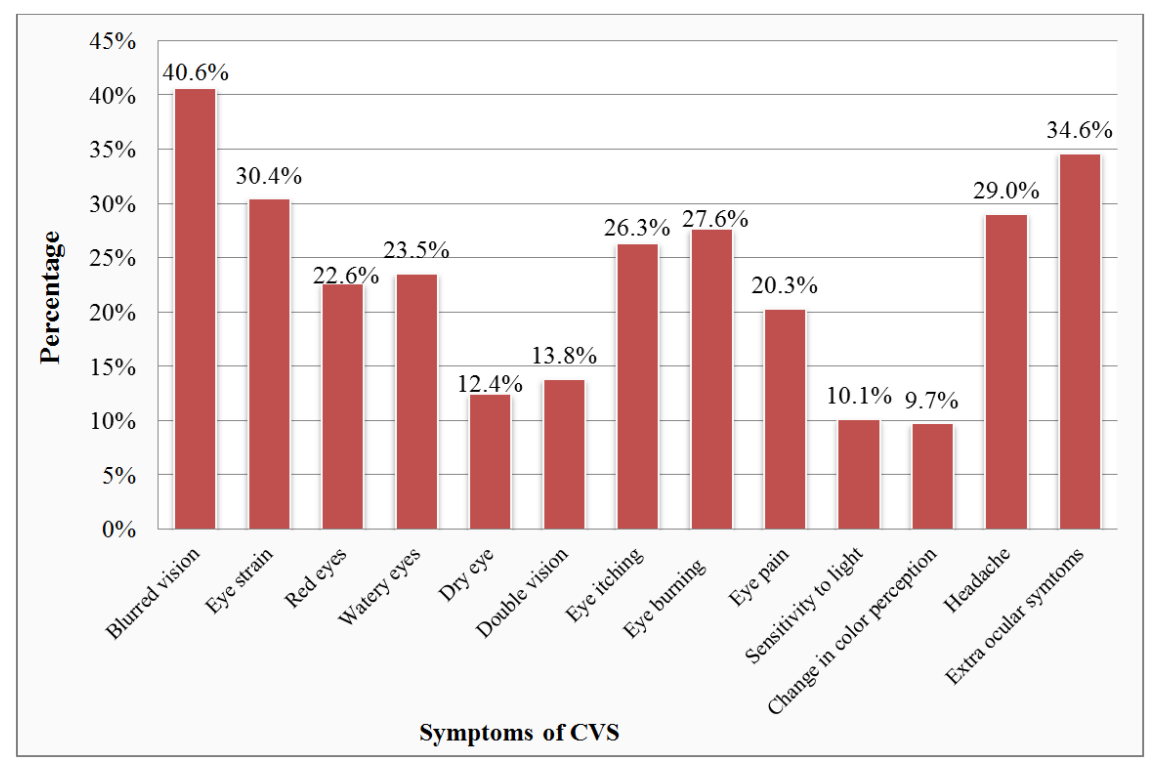

Figure 1. Frequency of CVS symptoms among secretary employees at Jimma University, Ethiopia, 2018 (n=164).

\subsection{Severity of Symptoms of Computer Vision Syndrome}

Participants were asked to report whether they had experienced none, mild, moderate, or severe problems during or after computer use. Of the total participants $(75.6 \%)$ suffering CVS, $45.94 \%$ developed mild, $44.72 \%$ moderate and $9.34 \%$ severe CVS symptoms. More specifically, it was found that mild blurred vision, watery eye, and a headache was experienced by 38 (17.5\%), 37 (17.1\%), and 31 (14.3\%) of study participants respectively. Light sensitivity $12(5.5 \%)$ and dry eye $9(4.1 \%)$ were the least mild symptoms experienced.

Similarly, blurred vision $46(21.2 \%)$ and extra-ocular symptoms $45(20.7 \%)$ were the most commonly reported moderate symptoms whereas double vision $5(2.3 \%)$ and change in color perception $5(2.3 \%)$ were equally the least moderate symptoms reported by study participants. Extraocular symptoms $12(5.5 \%)$ were the main severe problem reported followed by eye strain $10(4.6 \%)$ and eye itching 8 $(3.7 \%)$. However, no study participant $0(0.0 \%)$ reported severe double vision (Table 2).

Table 2. Frequency and severity of CVS symptoms among secretary employees in Jimma University, Ethiopia, 2018, ( $n=217)$.

\begin{tabular}{|c|c|c|c|c|}
\hline Symptoms of CVS & None n (\%) & Mild n (\%) & Moderate n (\%) & Severe n (\%) \\
\hline Blurred vision & $129(59.4)$ & $38(17.5)$ & $46(21.2)$ & $4(1.8)$ \\
\hline Eye strain & $151(69.6)$ & $23(10.6)$ & $33(15.2)$ & $10(4.6)$ \\
\hline Red eyes & $168(77.4)$ & $25(11.5)$ & $23(10.6)$ & $1(0.5)$ \\
\hline Dry eye & $190(87.6)$ & $9(4.1)$ & $16(7.4)$ & $2(0.9)$ \\
\hline Double vision & $187(86.2)$ & $25(11.5)$ & $5(2.3)$ & $0(0.00)$ \\
\hline Eye itching & $160(73.7)$ & $26(12.0)$ & $23(10.6)$ & $8(3.7)$ \\
\hline Pain in and around eyes & $173(79.7)$ & $20(9.2)$ & $16(7.4)$ & $8(3.7)$ \\
\hline Sensitivity to light & $195(89.9)$ & $12(5.5)$ & $7(3.2)$ & $3(1.4)$ \\
\hline Change in color perception & $196(90.3)$ & $15(6.9)$ & $5(2.3)$ & $1(0.5)$ \\
\hline Headache & $154(71.0)$ & $31(14.3)$ & $28(12.9)$ & $4(1.8)$ \\
\hline Extra ocular symptoms & $75(34.6)$ & $18(8.3)$ & $45(20.7)$ & $12(5.5)$ \\
\hline
\end{tabular}

\subsection{Predictors of Computer Vision Syndrome}

The variables that showed statistically significant association in the bivariate analysis were transferred and further analyzed in multivariable logistic regression to adjust for potential confounders and to identify predictors of 
computer vision syndrome. In multivariable analysis, longer duration of occupation, increased average time spent on the computer per day, lack of awareness about CVS, and its prevention measures and working on a computer without adjusting computer screen brightness was variables independently associated with CVS (Table 3). Secretary employees who had work experience of greater than or equal to ten years were three times (Adjusted odds ratio $[\mathrm{AOR}]=3.165 ; 95 \% \mathrm{CI}=1.16,8.57)$ more likely to experience CVS as compared to those worked 1 to $<5$ years. Study participants who spend their working time facing computer screen on average for greater than or equal to six hours per day were three times (AOR $=3.163 ; 95 \% \mathrm{CI}=1.52,6.59)$ higher to suffer from CVS when compared to those spending less than 6 hours per day. More importantly, working on a computer without adjusting computer screen brightness and lack of awareness about CVS and its prevention measures were 2.8 $(\mathrm{AOR}=2.81 ; 95 \% \mathrm{CI}=1.22,6.47)$ and 5.4 times $(\mathrm{AOR}=5.385$; $95 \% \mathrm{CI}=2.55,11.35)$ more likely to experience CVS when compared to their counterparts respectively.

Table 3. Bivariate and multivariate logistic regression analysis of risk factors associated with CVS in secretary employees working in Jimma University, Ethiopia, 2018, (n=217).

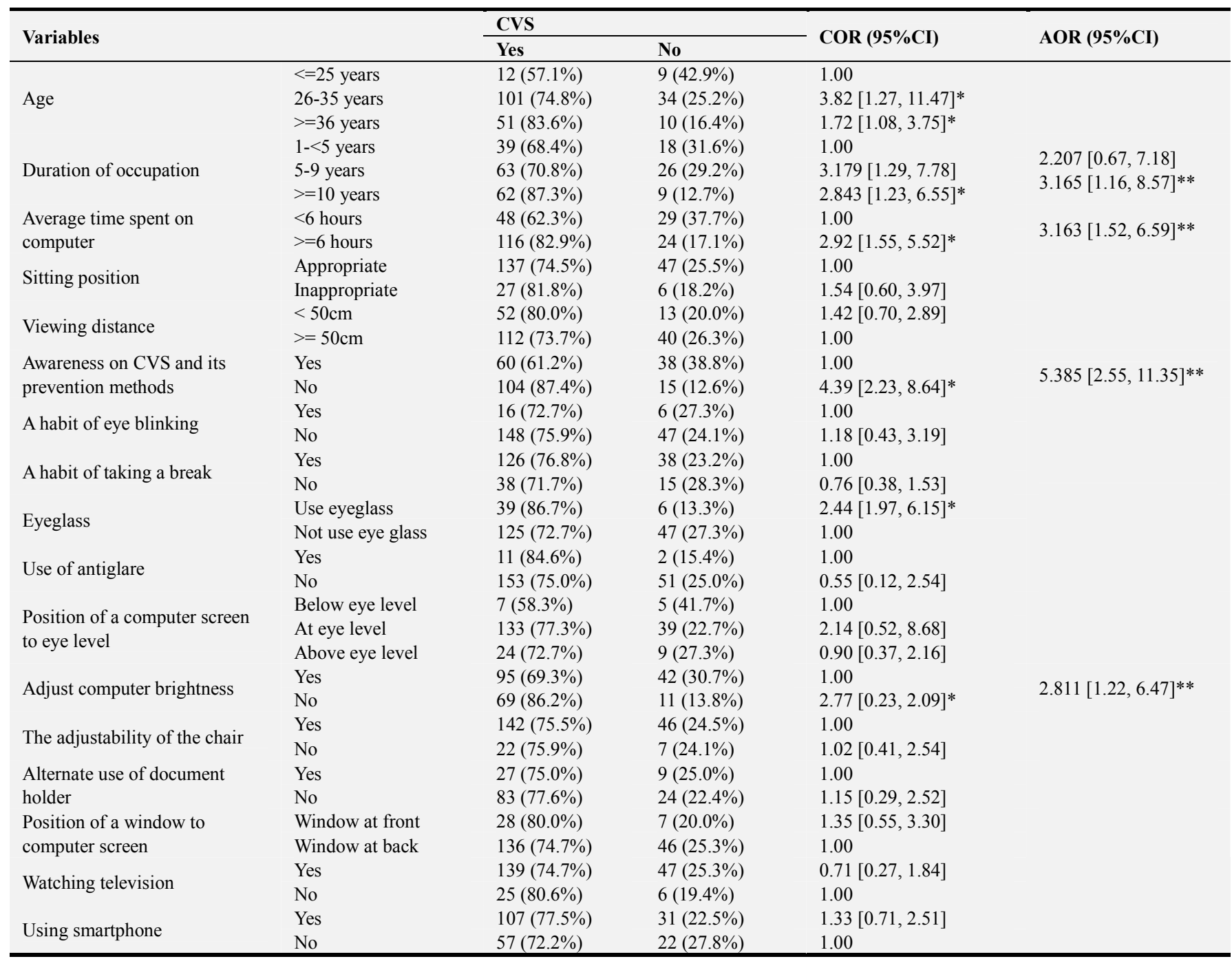

* Significant at $\mathrm{p} \leq 0.25, * *$ Significant at $\mathrm{p}<0.05,1.00$ - reference, COR- Crude Odds Ratio, AOR- Adjusted Odds Ratio

\section{Discussion}

The present study showed that the prevalence of CVS was $75.6 \%(95 \% \mathrm{CI}=70.0,81.1)$. This finding is in line with the study conducted in Gondar, Ethiopia among bankers [16] which reported the prevalence of CVS to be $73 \%$. This result is also similar with several studies from other countries which found prevalence of CVS to be $74 \%$ among computer users in Abuja, Nigeria [8], 72\% among university students in Ajman, United Arab Emirates [7] and 73.9\% among operator of the call center in São Paulo, Brazil [12]. The study found that the prevalence of CVS worldwide ranges from $25 \%$ to $93 \%$ [11].

The result of this study is lower than the study conducted among university engineering students in Chennai [2] and Malaysia [20] which reported the prevalence of CVS $81.9 \%$ and $89 \%$ respectively. The possible reason may be university students use computers and other electronic devices for a 
longer time for studying than secretary employees. Moreover, in our study, only the symptoms which lasted at least one week were considered as symptoms of CVS whereas these studies had no specification on the duration of symptoms and therefore even transient symptoms might be included.

In contrast, the finding of our study is higher than the study conducted among office workers in Sri Lanka [12] and information technology professionals in Chennai [13] that found the prevalence of CVS $67.4 \%$, and $69.3 \%$ respectively. The higher prevalence observed in our study may be due to the involvement of neck, back and shoulder pain as a symptom of CVS which has been also considered as an extraocular symptom of CVS in many studies [8, 12], whereas their definition of CVS consisted only of ocular/visual symptoms.

CVS is an umbrella term that covers a wide variety of visual/ocular and extra-ocular symptoms [6]. In the present study, blurred vision (40.6\%), extra-ocular symptoms (34.6\%), and eyestrain (30.4\%) were the most common reported symptoms whereas a change in color perception (9.7\%) was the least complaint. Similarly, a study conducted in Gondar among bankers reported blurred vision (42.4\%) as the most frequent complaint [16]. Moreover, eyestrain and blurred vision were the most commonly reported symptoms among computer users in Benin, Nigeria [21]. Al Rashidi et al. reported that the majority $(62.14 \%)$ of participants presented with eye strain [22].

In contrast to our findings, a study conducted in Pakistan among university students reported irritation of eyes (48\%), headache (38\%), and burning sensation $(33 \%)$ as the most frequent complaints [20]. Among Sri Lankan, computer workers headache was complained by $45.7 \%$ whereas changes in color perception were reported by $9.3 \%$ study participants [10]. This difference could be attributed to differences in study participants' occupation and pain threshold, sampling technique, and sample size.

CVS is a problem that is caused by several factors. The present study found an increased average time spent on the computer per day as a predictor of CVS and thus, secretaries spending greater than or equal to 6 hours per day on a computer was 3 times more likely to suffer CVS when compared to their counterparts. Mowatt et al. found results consistent with our study where $75 \%$ of people who spend $>6$ hours a day on the computer have more visual problems than those who do not [23]. Several studies have shown that an increase in the number of hours spent on a computer increases the risk of developing CVS significantly $[12,24]$.

Long hours working/focusing on computer screens decreases the speed of blinking from 16-20 normal blink rate to $6-8$ blinks/minute and the eye exposure to the free air increases, this would lead to reduced tear layer thickness over the inferior cornea, resulting in greater tear evaporation thereby causing symptoms of CVS [26].

In contrast, a study conducted in Gondar among bankers found no significant association between working hours per day and CVS [16]. The reason may be related to a difference in working hour's categorization and occupational difference.
Study participants in this area may most often take frequent breaks to give services to customers resulting lesser average time spent on a computer per day than secretaries. Likewise, the study conducted in Italy also didn't find any association between the duration of the computer use and CVS [25].

The prolonged duration of occupation was another factor significantly associated with CVS. Secretary employees working for greater than or equal to 10 years in the current position were three times higher to experience CVS as compared to those worked 1 to $<5$ years. Consistently, a study conducted by Ranasinghe et al., among computer office workers in Sri Lanka reported that increased duration of occupation was significantly associated with CVS [10]. Gupta et al. also found a similar result [5].

However, the study conducted by Arumugam et al. did not found significant association [13]. They explained the reason for not association as the sample size for those variables were possibly not adequate.

Working on a computer without adjusting the brightness of the screen was also a predictor of CVS. Study participants working on a computer without adjusting computer screen brightness was 2.8 times at high risk to develop CVS when compared to their counterparts. A study conducted in Uttar Pradesh, India among computer operators working in different offices and banks supported that symptoms of CVS were significantly reported by more subjects who work with computers without adjusting the brightness of the screen [26].

Brightness is one of the key features of a computer screen, which should be adjusted to provide balance with room lighting and maximum visibility. Brightness causes images and words on a screen to become blurry especially at its edge. Blurred images are known to cause stimulation of accommodation which leads to the ciliary muscle to tire easily and develop symptoms of CVS like blurred vision and eyestrain. Adjustment of the brightness level according to the workplace significantly reduces CVS symptoms like eyestrain and watering [26, 27]. However, in the study among computer office workers in Sri Lanka adjusting the brightness of the screen was not significantly associated with CVS [10]. The reason may be attributed to the difference in knowledge about CVS prevention strategies.

Moreover, awareness about CVS and its prevention measures was strongly associated with CVS in the current study. Studies show that most problems associated with computer use are caused by insufficient knowledge about safe computer usage. Sufficient knowledge about CVS and its preventive measures would minimize or prevent the occurrence of CVS [8, 11]. We couldn't found a study to compare and contrast this variable. Important factors such as sitting position, viewing distance, a habit of taking a break, the position of a computer screen to eye level, and others were not associated with CVS in our study.

There are certain limitations to this study. First, the obtained data on symptoms of computer vision syndrome was based on the subjective report by study participants and this may lead to over or underestimation of the prevalence of computer vision syndrome. Second, since the study was 
cross-sectional, it limits the establishment of the casual association and can only demonstrate an association between CVS and identified risk factors. Moreover, the sample size might be small for generalizing.

\section{Conclusion}

According to the present study, computer vision syndrome was highly prevalent among secretary employees working at Jimma University, where about three-fourths of the study participants suffered from CVS. The most common reported symptoms of CVS were blurred vision, extra-ocular symptoms, and eyestrain whereas a change in color perception was the least complaint. Prolonged duration of occupation, increased average time spent on the computer per day, lack of awareness about CVS, and its prevention measures and not adjusting computer screen brightness were found to be factors independently associated with computer vision syndrome. Therefore, Jimma University and other concerned bodies should arrange training program to increase awareness on CVS and its prevention measures, and/or any other means to minimize the risk of suffering CVS.

\section{Availability of Data and Materials}

The original data for this study are available from the corresponding author on reasonable request.

\section{Funding}

This study was funded by Jimma University. Ethical clearance was obtained from Institutional Review Board of Jimma University with reference number IHRPGD/268/18.

\section{Disclosure}

The funder had no role in study design, data collection and analysis, decision to publish, or preparation of the manuscript.

\section{Conflicts of Interest}

All the authors do not have any possible conflicts of interest.

\section{Authors' Contributions}

MT conceived research idea, designed the study, collected data, analyzed it, interpreted the result, and prepared the manuscript for publication. MI conceived the study, supervised the data collection, and reviewed the draft of the manuscript. YM participated in designing the study, supervision of the research project, and reviewing of the draft of the manuscript. LT and AA participated in designing the study, analyzed the result, and prepared the manuscript for publication.

\section{Acknowledgements}

The authors would like to express their appreciation to Jimma University for funding this research project. They would like to extend their deepest gratitude to all study participants and data collectors for their willingness and cooperation in this study.

\section{References}

[1] K. S Dhiman, D. K. Ahuja, and S. K. Sharma, "Clinical efficacy of Ayurvedic management in computer vision syndrome," Journal of Research in Ayurveda, Vol. 33, no. 3, pp. 391-394, 2012.

[2] M. Logaraj, V. Madhupriya, and S. Hegde, "Computer vision syndrome and associated factors among medical and engineering students in Chennai," Annals of Medical and Health Sciences Research, Vol. 4, no. 2, pp. 179-185, 2014.

[3] T. Akinbinu and Y. Mashalla, "Impact of computer technology on health: Computer Vision Syndrome," Medical Practice and Reviews, Vol. 5, no. 3, pp. 20-30, 2014.

[4] J. K. S. Parihar, V. K. Jain, P. Chaturvedi, et al., "Computer and visual display terminals vision syndrome (CVDTS)," Medical Journal Armed Forces India, Vol. 72, no. 3, pp. 270 276.

[5] N. Gupta, T. Moudgil and B. Sharma, "Computer Vision Syndrome: Prevalence And Predictors Among College Staff And Students," IOSR Journal of Dental and Medical Sciences, Vol. 15, no. 9, pp. 28-31.

[6] American Optometry Association, "Guide to Clinical Aspects of Computer Vision Syndrome," Association AO, St. Louis, MO, USA. 2002.

[7] N. Shantakumari, R. Eldeeb, J. Sreedharan and K. Gopal, "Computer Use and Vision Related Problems Among University Students In Ajman, United Arab Emirate," Annals of Medical and Health Sciences Research, Vol. 4, no. 2, pp. 258-263, 2014.

[8] T. R. Akinbinu and Y. J. Mashalla, "Knowledge of computer vision syndrome among computer users in the workplace in Abuja, Nigeria," Journal of Physiology and Pathophysiology, Vol. 4, no. 4, pp. 58-63, 2013.

[9] N. A. Charpe and V. Kaushik, "Computer Vision Syndrome (CVS): Recognition and Control in Software Professionals," Journal of Human Ecology, Vol. 28, no. 1, pp. 67-69, 2009.

[10] P. Ranasinghe, S. Wathurapatha, Y. S. Perera et al., "Computer vision syndrome among computer office workers in a developing country," BMC Research Notes, Vol. 9, pp. 1-9, 2016.

[11] S. Ramzan and M. I Shahid, "Impact of computer vision syndrome on the health of computer usage bank employee," Journal of Computer Science Engineering, Vol. 2, no. 7, pp. 10-53, 2016.

[12] E. C Sa, M. Ferreira, and L. E Rocha, "Risk factors for computer visual syndrome among operators of two call centers in São Paulo, Brazil," Work IOS press, Vol. 41, no. 1, pp. 3568-3574, 2012. 
[13] S. Arumugam, K. Kumar, R. Subramani, and S. Kumar, "Prevalence of Computer Vision Syndrome among Information Technology Professionals Working in Chennai," World Journal of Medical Sciences, Vol. 11, no. 3, pp. 312314, 2014.

[14] J. Bali, N. Navin, and B. R. Thakur, "Computer vision syndrome: A study of the knowledge, attitudes, and practices in Indian Ophthalmologists," Indian Journal of Ophthalmology, Vol. 55, no. 4, pp. 289-294, 2007.

[15] H. M. Hassan, S. Ehsan, H. S. Arshad, "Frequency of Computer Vision Syndrome \& Ergonomic Practices among Computer Engineering Students," International Journal of Science and Research, Vol. 5, no. 5, pp. 121-125, 2016.

[16] N. L. Assefa, D. Z. Woldemichael, D. H. Anbesse, and H. W. Alemu, "Prevalence and associated factors of computer vision syndrome among bank workers in Gondar City, northwest Ethiopia," Clinical Optometry, Vol. 9, pp. 67-76, 2017.

[17] A. Crespo, M. Segu, and E. Ronda, "A reliable and valid questionnaire were developed to measure computer vision syndrome at the workplace," Journal of Clinical Epidemiology, Vol. 68, no. 6, pp. 662-673, 2015.

[18] A. Akms, S. Alam, and M. Do, "Computer vision syndrome," The ORION Medical Journal, Vol. 32, no. 3, pp. 692-693, 2009.

[19] K. Noreen, Z. Batool, T. Fatima, and T. Zamir, "Prevalence of Computer Vision Syndrome and Its Associated Risk Factors among Under Graduate Medical Students," Pakistan Journal of Ophthalmology, Vol. 32, no. 3, pp. 140-146, 2016.

[20] C. Chu, M. Rosenfield, K. Portello, and J. Benzoni, "A comparison of symptoms after viewing text on a computer screen and hardcopy," Ophthalmic and Physiological Optics, Vol. 31, no. 1, pp. 29-32, 2011.

[21] C. Stella, A. E. Chiemeke and B. A Olajire, "Evaluation of Vision-Related Problems amongst Computer Users in Benin,
Nigeria," Proceedings of World Congress on Engineering, Vol. 1, no. 5, pp. 978-988, 2007.

[22] H. Sultan, Al Rashidi, and H. Alhumaidan, "Computer vision syndrome prevalence, knowledge and associated factors among Saudi Arabia University Students: Is it a serious problem?" International Journal of Health Sciences, Vol. 11, no. 5, pp. 17-19, 2017.

[23] L. Mowatt, C. Gordon, A. Babu and T. Jones, "Computer vision syndrome and ergonomic practices among undergraduate university students," International Journal of Clinical Practice, Vol. 72, no. 1, pp. 1-7, 2017.

[24] R. A. Ambade, A. K. Ambade and M. M. Sagdeo, "Musculoskeletal disorders, Asthenopia and associated risk factors in computer workers of Hingna Taluka of Nagpur: A cross-sectional study," Scholars Academic Journal of Biosciences, Vol. 4, no. 3, pp. 297-303, 2016.

[25] F. Mocci, A. Serra, G. A. Corrias, "Psychological factors and visual fatigue in working with video display terminals," Occupational and Environmental Medicine, Vol. 58, no. 4, pp. 267-271, 2001.

[26] S. Agarwal, D. Goel, A. Sharma, "Evaluation of the Factors which Contribute to the Ocular Complaints in Computer Users," Journal of Clinical and Diagnostic Research, Vol. 7, no. 2, pp. 331-335, 2013.

[27] Z. Yan, Chen H, L. Hu, and F. Lu, "Computer Vision Syndrome: A widely spreading but largely unknown epidemic among computer users," Computers in Human Behavior, Vol. 24, no. 5, pp. 2026-2042, 2008.

[28] Seguí, M. M.; Cabrero-García, J.; Crespo, A.; Verdú, J.; Ronda, E. A reliable and valid questionnaire was developed to measure computer vision syndrome at the workplace. J. Clin. Epidemiol, Vol. 38, pp. 662-673, 2015. 